\title{
Epidemiology of Prenatal Genetic and Environmental Factors of Mental Retardation in Cuba
}

\author{
Araceli Lantigua Cruz, MD, PhD, Miriam Portuondo Sao, MD, MSc, Teresa Collazo Mesa, PhD, Roberto Lardoeyt Ferrer, MD, PhD
}

\begin{abstract}
Introduction One of the most sensitive disabilities in human beings is intellectual disability. In April, 2003, a 10-month study was completed of all persons in Cuba with mental retardation (MR), producing results that included epidemiological variables on a national scale.

Objective Through follow-up research, this paper describes and analyzes 4 prenatal factors associated with MR: Down syndrome (DS), fragile X syndrome (FXS), consanguinity, and maternal alcohol use during pregnancy, in order to provide recommendations for health system decision-makers on consolidating prevention strategies at the community level and improving individual attention to persons with MR.

Materials \& Methods All studies were carried out on the basis of strict ethical principles. Data for the 4 prenatal factors was gleaned from the national study's database. Additional data on affected individuals was obtained through home visits. A previously developed screening instrument was used for clinical genetic analysis to classify possible MR causal factors as prenatal, perinatal, postnatal, psychosis, and unclassifiable. Prenatal included causal factors such as: genetic (by clinical genetic examination, metabolic screening in urine, and routine karyotypes); nonspecific (evidence of prenatal causal factor without diagnosis of genetic or environmental etiology); and environmental (prenatal medical history of biological, physical, or chemical teratogens, endocrine-metabolic diseases, or other maternal diseases known to affect fetal neurodevelopment). Frequency, prevalence, and percentages were reported using a descriptive statistical method. Impact of interventions and actions over time were also compared.
\end{abstract}

Results MR prevalence in Cuba is $1.25 \%$, lower than the value of $2 \%-3 \%$ reported in developed countries. National prevalence of DS was found to be 4.3 per 10,000 population, representing $22.1 \%$ of persons with MR attributed to an ascertained genetic cause. FXS prevalence in a population of individuals of both sexes with MR, initially classified as nonspecific prenatal, psychosis, and unclassifiable, was 2.5 per 1,000 of that population; however, in males of the same population, prevalence was 3.7 per 1,000. At this first stage, such results indicate that this syndrome contributes biologically to the 1.46:1 male/female ratio among the 140,489 individuals with MR. Maternal alcohol use during pregnancy was found in $4.22 \%$ of persons with MR and consanguinity was present in $6.89 \%$ of the population with MR $(10.9 \%$ of persons with mild prenatal MR and $14.2 \%$ with severe MR). This national data is subdivided by regions and provinces in this paper.

Conclusions Prevalence of MR in Cuba is lower than reference values for developed countries. Knowledge generated by this study about 4 specific causes of MR constitutes pioneering research in the Cuban context, contributing to the field of medical genetics. The results offer the basis for formulation of new scientific contributions related to MR genetics as well as preventive approaches to such genetic factors as consanguinity and to environmental factors such as maternal alcohol use during pregnancy, which affect or target embryo-fetal development of the nervous system.

Keywords: Epidemiology; Mental retardation; Down syndrome; Fragile X syndrome; Consanguinity; Maternal alcohol use; Immunohistochemical test; Molecular genetics; Cytogenetics; Genetic

\section{INTRODUCTION}

In the etiology of mental retardation (MR), environmental factors may involve the prenatal, perinatal, or postnatal stages of development, while genome-attributable defects are conceptually prenatal, independent of the neurodevelopmental moment when the cognitive defect manifests. Thus in general, the origins of mental retardation can be classified as prenatal, perinatal, and postnatal.

These causal criteria were put forward by Gustavson et al. in Sweden,[1] who added as an independent category psychoses with mental retardation, describing as unclassifiable those cases with no criteria for discerning their etiology.

A group of researchers in Cuba has worked in this field for over 20 years, incorporating the various factors that may cause or be associated with the appearance of MR.[2,3] In April 2003, a 10-month national study was concluded by the Cuban national health sys- tem, revealing an MR prevalence of $1.25 \%$ in total population.[3] Based on the study, the objective of the research for this paper is to describe and analyze 4 prenatal factors with recognized causal association to MR - Down syndrome, fragile $X$ syndrome, consanguinity, and maternal alcohol use during pregnancy - in order to provide recommendations for health system decision-makers on consolidating prevention strategies at the community level and improvement of individual attention to persons with MR.

\section{MATERIALS AND METHODS}

Data for analysis of the 4 prenatal factors was gleaned from the national study's database, protected under the study's protocol by the National Disabilities Program headquartered at the National Center for Medical Genetics, and to which the principal author has authorized access.[3] After affected individuals were identified, additional data was obtained through home visits made in each community, municipality, and province by Master's Degree 


\section{Original Scientific Articles}

candidates in the field of Genetic Counseling, and also through specialized evaluations.

The national study, as well as this follow-up study, were carried out on the basis of strict ethical principles, complying with all applicable requirements regarding human subjects set forth in international documents such as the World Medical Association Declaration of Helsinki (as amended, 2004)[4] and the UNESCO Declaration of 2003,[5] including confidentiality of information provided by persons and their families, as well as of the results of blood screenings. Both studies were based on voluntary participation, obtaining informed consent of parents or guardians and assent by intellectually disabled persons (with mild mental retardation, MMR) who participated in the study and including informed consent for karyotype blood analysis or molecular study for detection of the FMR1 mutation.[3,6]

\section{Detailed Methodology}

Cognitive disability was determined by teams from Orientation and Diagnostic Centers (CDO), including professionals from various fields (psychologists, specialists in special education, psychometricians, pedagogues, speech therapists) who applied intelligence (IQ) tests and evaluated behavior of persons with suspected mental retardation, assessing degree of MR severity.[7]

A previously developed screening instrument was used for clinical genetic analysis by professionals trained in its use, permitting classification of possible MR causal factors. Working as a team, these professionals classified causal factors as prenatal, perinatal, postnatal, psychosis, and unclassifiable, according to parameters discussed by Gustavson.[1] This instrument was applied by a family physician and a special education specialist. In cases where there were doubts as to classification, patients were visited and examined by clinical geneticists and other specialists as necessary (neurologists, pediatricians, etc.). Furthermore, these individuals received follow-up visits by family medicine specialists or university-level nurses (260 in total throughout the country, in all provinces and municipalities) as part of their Genetic Counseling Master's research (with 4th-, 5th- and 6th-year medical students, academic year 2004-2005).

The group classified as prenatal included the following causal factors:

- Genetic: by clinical genetic examination, metabolic screening in urine, routine karyotypes. Diagnosis of genetic conditions and etiology of congenital defects previously carried out in clinical genetics services were taken into consideration.

- Nonspecific: evidence of prenatal causal factor without diagnosis of genetic or environmental etiology.

- Environmental: prenatal medical history of biological, physical, or chemical teratogens, endocrine-metabolic diseases, or other maternal diseases known to affect fetal neurodevelopment.

Cases were classified as perinatal and postnatal when a history of environmental factors such as perinatal injury, infection, intoxication, or accidents could explain the cause of MR, provided there was no evidence of prenatal damage. Persons were considered unclassifiable who presented with nonsyn- dromic MR with neither consanguinity nor first degree familial addition or X-linked inheritance, without evidence of other classifications and when physical examination revealed no dysmorphism.

Psychosis was considered when there was a diagnosis of autism or other infantile-onset psychosis accompanied by mental retardation, and which was not described by any known genetic syndrome.

Information on the sex of subjects was obtained from the national study's database, and analysis considered the male-female ratio in Cuba's total population, and among MR individuals compared to total population. Gender relation was considered among individuals whose causal factors were defined as of a prenatal origin, psychosis, and unclassifiable. The World Health Organization (WHO) MR categories were used: a) mild mental retardation (MMR) for individuals with an intelligence quotient (IQ) between 50 and 70, and b) severe mental retardation (SMR) for individuals with an IQ below 50.[7] In all cases, the population of persons with MR was divided into 2 age groups: $0-14$ years and $\geq 15$ years.

Two genetic factors associated with MR were selected for this research. The first was a chromosomal cause, Down syndrome (DS), which presents evident clinical phenotypic features from birth, permitting dysmorphologic identification including either MR or neurodevelopmental retardation, depending on age.

During the national study, routine karyotype screening was performed on all individuals clinically diagnosed with DS but not previously screened. Priority was given to those with family histories of DS and those whose karyotype definition would make genetic counseling possible for relatives in their reproductive years, in order for them to make more informed reproductive decisions. Based on these results, the detected frequencies of trisomies 21, $\mathrm{D} / \mathrm{G}$ or $\mathrm{G} / \mathrm{G}$ translocations and mosaicisms were analyzed.

The second genetic cause selected was fragile $X$ syndrome (FXS). Two methods were used for FXS diagnosis: first, an immunohistochemical test,[8] used only in Havana City[9] to screen all males presenting with MR, excluding persons diagnosed with known genetic syndromes such as DS and those whose condition was unequivocally associated with perinatal and postnatal environmental factors. In the rest of the country, diagnosis was made by clinical examination, using the phenotypic score (minimum percentage of 12 for adults and 10 for children);[10] a molecular study was indicated for only one male with MR in families where more than one male presented clinical evidence of FXS.

In all cases suggesting FXS - whether determined by immunohistochemical screening or clinical evidence - molecular characterization of FMR1 gene mutation was carried out by Southern blot direct method,[11] using Hind III and Eag I enzymes, and Pp2 probe.

Consanguinity (marriage between first cousins, uncles and nieces or aunts and nephews, or other kinship) was taken into account as a prenatal genetic causal factor when revealed during the interview. 
To define maternal alcohol use during pregnancy as a possible cause of MR, persons with this history but who presented other known genetic syndromes were excluded. Maternal alcohol use was considered only in cases of persons with this history who presented a dysmorphic constellation characteristic of fetal alcohol syndrome (FAS), or who manifested nonsyndromic MR with this prenatal history.[12]

Frequency, prevalence, and percentages were reported using a descriptive statistical method.[13] Impact of interventions and actions through time were also compared.

Taking into consideration population density, the country was divided into the following regions for data analysis:
Table 1: Mental Retardation (MR) by Age Group, Sex, Severity, and Selected Causes in Total Population, Cuba

$\begin{array}{lcccc}\text { MR Classification } & \text { Prenatal } & \text { Psychosis } & \text { Unclassifiable } & \text { Total } \\ \text { MMR } & 1.5 \mathrm{M}: 1 \mathrm{~F} & 1.6 \mathrm{M}: 1 \mathrm{~F} & 1.7 \mathrm{M}: 1 \mathrm{~F} & 1.6 \mathrm{M}: 1 \mathrm{~F} \\ 0-14 \text { years } & 1.5 \mathrm{M}: 1 \mathrm{~F} & 1.7 \mathrm{M}: 1 \mathrm{~F} & 1.8 \mathrm{M}: 1 \mathrm{~F} & \\ \geq 15 \text { years } & 1.7 \mathrm{M}: 1 \mathrm{~F} & 1.6 \mathrm{M}: 1 \mathrm{~F} & 1.5 \mathrm{M}: 1 \mathrm{~F} & \\ \text { SMR } & 1.3 \mathrm{M}: 1 \mathrm{~F} & 1.5 \mathrm{M}: 1 \mathrm{~F} & 1.1 \mathrm{M}: 1 \mathrm{~F} & 1.3 \mathrm{M}: 1 \mathrm{~F} \\ 0-14 \text { years } & 1.4 \mathrm{M}: 1 \mathrm{~F} & 2.4 \mathrm{M}: 1 \mathrm{~F} & 1.6 \mathrm{M}: 1 \mathrm{~F} & \\ \geq 15 \text { years } & 1.33 \mathrm{M}: 1 \mathrm{~F} & 1.5 \mathrm{M}: 1 \mathrm{~F} & 1.1 \mathrm{M}: 1 \mathrm{~F} & \end{array}$

M:male F:female MMR: Mild Mental Retardation SMR: Severe Mental Retardation

Source: Analysis of results obtained from the National Study of Disabilities and Persons with Mental Retardation in Cuba, National Medical Genetics Center, Havana, 2003; and follow-up study reflected in this article.
Western region: Pinar del Río, Havana, Havana City, and Matanzas provinces, plus the special municipality Isla de la Juventud (Isle of Youth).

Central region: Cienfuegos, Villa Clara, Sancti Spíritus, Ciego de Ávila, and Camagüey provinces.

Eastern region: Las Tunas, Holguín, Granma, Santiago de Cuba, and Guantánamo provinces.

\section{RESULTS}

In the national study 140,489 individuals with intellectual disability were detected. Of these, 79,442 presented mild mental retardation (MMR) and 61,047 severe mental retardation (SMR). Global prevalence of MR is $1.25 \%$.[3]

Figure 1 shows global prevalence of MR increasing towards highest values in the eastern region, as is the case with MMR.

In Table 1, results for MR in males and females are illustrated according to age, severity, and selected causes. It should be noted that males presented more frequently in the MMR group, as well as in the SMR group, although in the latter differences are smaller and more homogeneous.

\section{Down Syndrome}

4,919 individuals with Down syndrome were detected nationally for a prevalence of 4.3 per 10,000 population. Table 2 shows DS prevalence by province as per 10,000 population, and weight of DS as percent of all persons with MR, and as percent of MR cases of genetic origin.

Figure 1. Prevalence of Global Mental Retardation and MMR by Western, Central, and Eastern Regions, Cuba

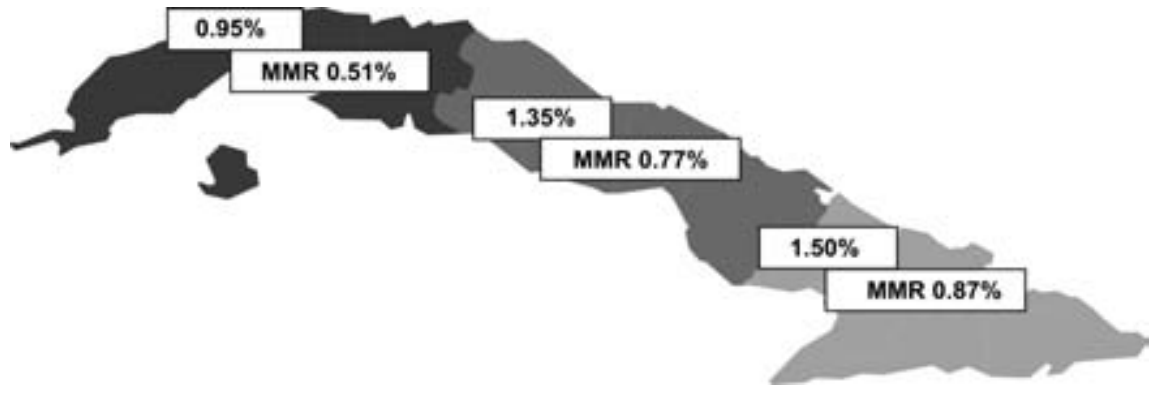

Source: Analysis of results obtained from the National Study of Disabilities and Persons with Mental Retardation in Cuba, National Medical Genetics Center, Havana, 2003.
Figure 2: Prevalence of Down Syndrome by Age, Cuba

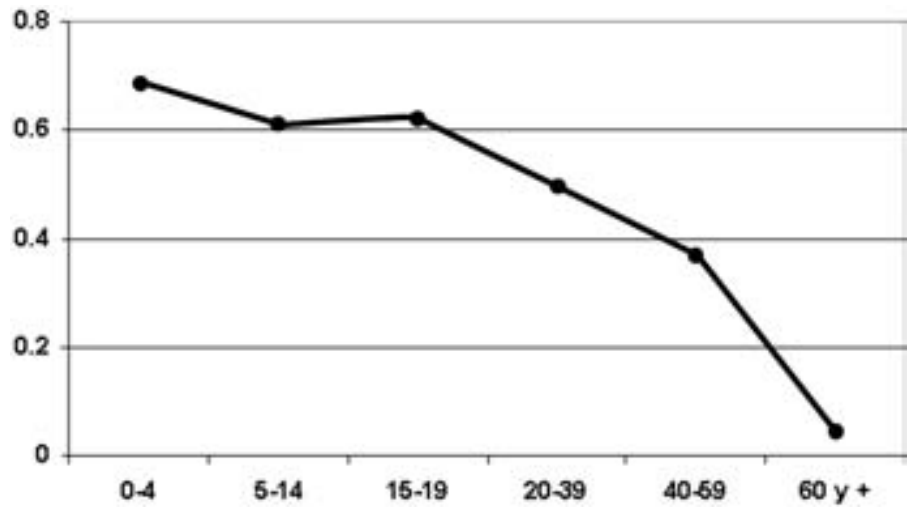

Source: Analysis of results obtained from the National Study of Disabilities and Persons with Mental Retardation in Cuba, National Medical Genetics Center, Havana, 2003.

Figure 2 shows declining DS prevalence with increasing age. The map in Figure 3 illustrates DS prevalence (per 10,000 population) in total population by region, as well as its distribution by age group (0-4 years and 5-14 years) and region. Differences can be observed, with slightly higher prevalence in total population in the western region and variable prevalence by age group.

The national screening studied 414 DS cases, and an additional 142 cases, which were previously studied by clinical geneticists or through institutional research,[2] for a total of 556 DS persons. Although there are a larger number of DS patients with karyotypes, these were not included in our results here since they were not available at the time research for this paper was carried out. The originating phenomena were distributed as follows: 513 due to trisomy $21(92.0 \%) ; 21 \mathrm{D} / 21$ or G/21 to translocation (3.8\%), and 22 to mosaicism (3.9\%).

\section{Fragile $X$ Syndrome}

Of the 658 males screened by immunohistochemical test in Havana City province, 61 males in 24 families presented full mutation of the FMR1 gene. In the rest of the country, af- 
Table 2: Prevalence of Down Syndrome (DS) by Province, Cuba

\begin{tabular}{|lccc|}
\hline Province & $\begin{array}{c}\text { DS prevalence in total } \\
\text { population (per 10,000) }\end{array}$ & $\begin{array}{c}\text { DS in persons } \\
\text { with MR (\%) }\end{array}$ & $\begin{array}{c}\text { DS in genetic-origin } \\
\text { MR (\%) }\end{array}$ \\
\hline Pinar del Río & 5.4 & 3.54 & 13.11 \\
\hline Havana Province & 4.7 & 4.05 & 20.60 \\
\hline Havana City & 4.4 & 6.94 & 58.38 \\
\hline Matanzas & 4.4 & 4.05 & 21.48 \\
\hline Isle of Youth & 4.1 & 3.91 & 17.82 \\
\hline Cienfuegos & 4.0 & 3.06 & 19.00 \\
\hline Villa Clara & 4.6 & 3.48 & 15.37 \\
\hline Sancti Spíritus & 3.6 & 3.09 & 41.18 \\
\hline Ciego de Ávila & 4.8 & 3.30 & 20.30 \\
\hline Camagüey & 4.1 & 2.83 & 23.67 \\
\hline Las Tunas & 3.3 & 2.47 & 32.35 \\
\hline Holguín & 4.0 & 2.49 & 19.32 \\
\hline Granma & 4.3 & 3.59 & 24.52 \\
\hline Santiago de Cuba & 4.3 & 2.60 & 17.44 \\
\hline Guantánamo & 4.8 & 2.89 & 16.02 \\
\hline Total & 4.3 & 3.50 & 22.07 \\
\hline
\end{tabular}

$* \mathrm{n}=140,489$

Source: Analysis of results obtained from the National Study of Disabilities and Persons with Mental Retardation in Cuba, National Medical Genetics Center, Havana, 2003.

Figure 3. Down Syndrome (DS) Prevalence by Age and Region, Cuba

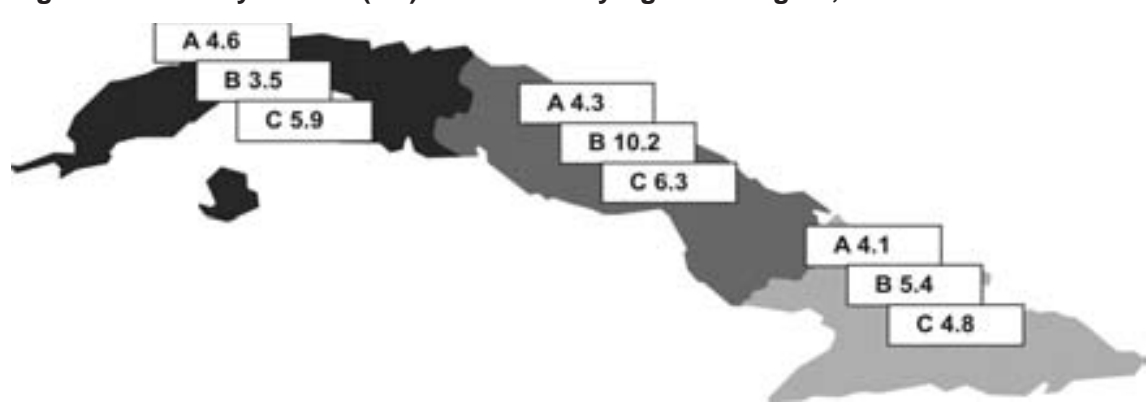

Key:

A: in general population. B: In population 0-4 years. C: In population 5-14 years. Per 10,000 pop. Source: Analysis of results obtained from the National Study of Disabilities and Persons with Mental Retardation in Cuba, National Medical Genetics Center, Havana, 2003.

Figure 4: Complete Mutation for FXS in Males with Mental Retardation, Etiology Initially Categorized as Prenatal Unspecific, Psychosis, or Unclassifiable, by Region, Cuba

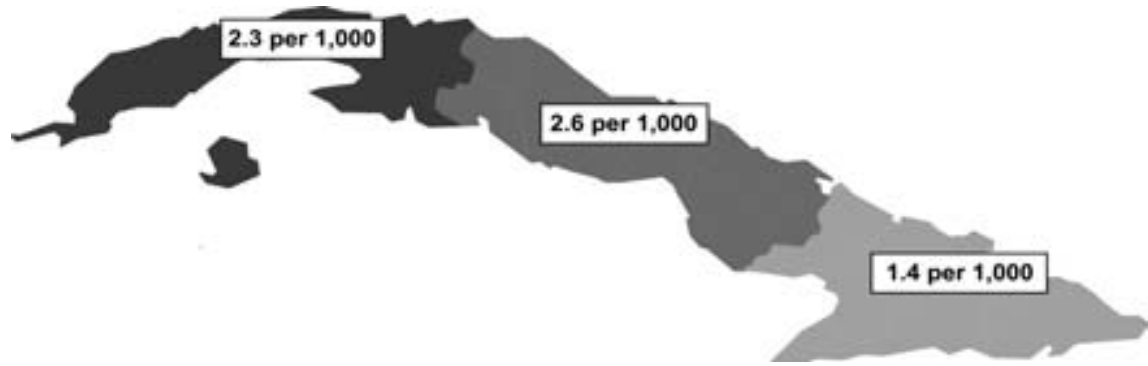

Source: Analysis of results obtained from the National Study of Disabilities and Persons with Mental Retardation in Cuba, National Medical Genetics Center, Havana, 2003; and follow-up study reflected in this article. ter clinical examination based on the established scoring, molecular studies of 245 males revealed another 86 mutations. Thus, of those presenting MR nationally, a total of 147 males manifested fragile $X$ syndrome with full mutation of FMR1 gene, and 21 heterozygotic females were detected with full mutation. Molecular study was indicated in 81 women who manifested MR and were related to men with a high clinical score for FXS.

FXS thus presents a prevalence of 2.5 per 1,000 in 66,794 MR persons of both sexes in Cuba whose origins were classified as prenatal, psychosis, and unclassifiable. Prevalence is 3.7 per 1,000 for males in that group $(39,332)$. This population of MR individuals was selected because in these groups it was possible to detect the clinical characteristics required for scoring as defined by De Vries[10] (craniofacial dysmorphism, autism, first-degree family antecedents with criteria of segregation for this dynamic mutation, macroorchidism, etc.).

In the male population with general MR, excluding those of perinatal and postnatal etiology $(50,381)$, FXS represented a prevalence of 2.9 per 1,000 . Figure 4 shows results for this population by region.

Greatest prevalence was registered in the central Cuban provinces, especially Cienfuegos, where frequency was 5.5 per 1,000 related to general MR population (excluding perinatal and postnatal).

\section{Consanguinity}

Consanguinity was present in $5.87 \%$ of all MR cases and in $11.98 \%$ of MR cases of prenatal etiology. However, interesting differences, which surpass the national frequency, were observed in several provinces, as seen in Table 3.

Of the 69,489 individuals with MMR (nationally, excluding Havana City and Sancti Spíritus provinces), 4,470 were offspring of consanguineous parents; of the 51,595 with SMR (excluding the same provinces), consanguinity was present in 3,976. In both, the kinship between parents was mainly first cousins; other kinships were those between more distant cousins or between uncles and nieces or aunts and nephews.

Figure 5 shows frequency of consanguinity for $\mathrm{MR}$ in total population by region, excluding $\mathrm{Ha}-$ vana City and Sancti Spíritus provinces.

\section{Alcohol in Etiology of MR}

A history of alcohol use during pregnancy was described in cases of 5,934 individuals with varying severity of MR. Of those, dysmorphic evidence by physical examination was detected in 1,408, while this history was also present in 3,760 indi- 
viduals with MR who showed no dysmorphic characteristics. The typical dysmorphic features of Fetal Alcohol Syndrome (FAS) were not clearly identified in 766 individuals.

Table 4 shows maternal alcohol use during pregnancy (MAP) associated with MR in the general population of persons with MR, and in persons with MR due to prenatal causes. Percentages presenting dysmorphic features or nonsyndromic MR are also shown.

Figure 6 represents maternal alcohol use in pregnancy associated with MR in Cuba, indicating the problem is more serious in the eastern region. As shown in Table 4, Havana City and Matanzas provinces stand out in the western region. In the central region, which has the lowest frequency of alcohol use associated with MR, Camagüey stands out with the highest alcohol use. Notice that from this province on, frequencies are high in the provinces of the eastern region, especially in Santiago de Cuba.

\section{DISCUSSION}

The prevalence of MR nationally is $1.25 \%$, lower than reference values for developed countries, reported between 2\%-3\%.[14] However, there are important regional differences that may be related to geographical and socio-cultural characteristics - both in the case of regions with lower prevalence, such as Havana City and Holguín, and those with higher prevalence, such as Santiago de Cuba and Guantánamo.[3] This aspect merits further study by researchers.

\section{Down Syndrome (DS) and Fragile X Syndrome (FXS)}

These two syndromes are analyzed in detail in our country, since they are reported as the most frequent genetic causes of MR worldwide.[14]

DS is the most frequent genetic cause of mental retardation. $[14,15]$ Its clinical diagnosis at any age is unequivocal for the majority of specialists working in the care of these persons. In our research, the clinical-genetic study of persons with mental retardation was carried out by specialists in clinical genetics who were present throughout the research. DS was $22.10 \%$ of the diagnoses of mental retardation of genetic etiology. Provinces such as Havana City, Sancti Spíritus, and Las Tunas exhibit the highest percentages of DS as a genetic cause of MR (Table 2). Variations found may be due to several reasons, mortality among them. 3,008 DS cases in all of Cuba were older than 20 years (61.3\%); Havana City province makes up $20.2 \%$ of this population. In turn, this was the province with more DS patients older than 60.72 persons with DS in Cuba are older than $60,1.5 \%$ of all persons with DS. From the age of 20 forward, prevalence of DS decreases, as shown in Figure 2.

The DS life chart, put forward by Baird and Sadovnick,[15] establishes that $85 \%$ of DS babies survive the first year of life; $80 \%$ survive 10 years, and $50 \%$ live more than 20 years. Our results in relation to this life chart deserve a more detailed analysis which goes beyond the objectives of this paper, but they generate questions and hypotheses for further study.
Table 3: Consanguinity in Mental Retardation (MR): By Province for Total MR Population and for MR Population of Prenatal Cause According to Severity (MMR or SMR)

\begin{tabular}{|c|c|c|c|c|}
\hline \multirow[t]{2}{*}{ Province } & \multirow[t]{2}{*}{$\begin{array}{l}\% \text { Consanguinity } \\
\text { in MR Population* }\end{array}$} & \multicolumn{3}{|c|}{$\begin{array}{l}\% \text { Consanguinity in MR } \\
\text { of Prenatal Cause }\end{array}$} \\
\hline & & Total & MMR & SMR \\
\hline Pinar del Río & 8.54 & 18.23 & 18.32 & 21.79 \\
\hline Havana Province & 5.00 & 10.21 & 4.48 & 11.87 \\
\hline Havana City & ** & $\star \star$ & $\star *$ & $\star \star$ \\
\hline Matanzas & 5.59 & 11.56 & 10.36 & 12.86 \\
\hline Isle of Youth & 5.97 & 9.87 & 5.33 & 7.71 \\
\hline Villa Clara & 6.44 & 13.27 & 12.04 & 15.07 \\
\hline Cienfuegos & 5.96 & 12.89 & 9.15 & 9.26 \\
\hline Sancti Spíritus & ** & $\star \star$ & ** & ** \\
\hline Ciego de Ávila & 6.56 & 13.50 & 9.48 & 21.17 \\
\hline Camagüey & 7.38 & 17.30 & 6.55 & 8.52 \\
\hline Las Tunas & 12.36 & 28.07 & 13.16 & 16.30 \\
\hline Holguín & 10.29 & 23.43 & 32.70 & 35.59 \\
\hline Granma & 9.69 & ** & ** & ** \\
\hline Santiago de Cuba & 5.43 & 10.52 & 5.18 & 5.74 \\
\hline Guantánamo & 7.21 & 14.83 & 36.70 & 38.00 \\
\hline TOTAL & 6.89 & 11.98 & 10.91 & 14.19 \\
\hline
\end{tabular}

${ }^{*} \mathrm{n}=121,084$ excluding Havana City and Sancti Spíritus provinces.

** Havana City and Sancti Spíritus provinces are still pending in this study, and Granma province shows global values but with no specificity for MR due to prenatal causes. Source: Analysis of results obtained from the National Study of Disabilities and Persons with Mental Retardation in Cuba, National Medical Genetics Center, Havana, 2003.

Prevalence values are quite homogeneous in the three regions of the country. However, these differ for the populations aged 0-4 years and 5-14 years in the three regions (Fig.3). Low prevalence can be seen in the $0-4$ year-old population in the west, and high prevalence in the central and mid-eastern regions.

We cannot explain these differences with certainty, but they may be due to at least two reasons: greater coverage of the program for prenatal detection of DS in the last 6 years in Havana City (which may lead to fewer births with DS), and/or lower mortality

Figure 5: Consanguinity in Parents of Persons with Mental Retardation by Region, Cuba*

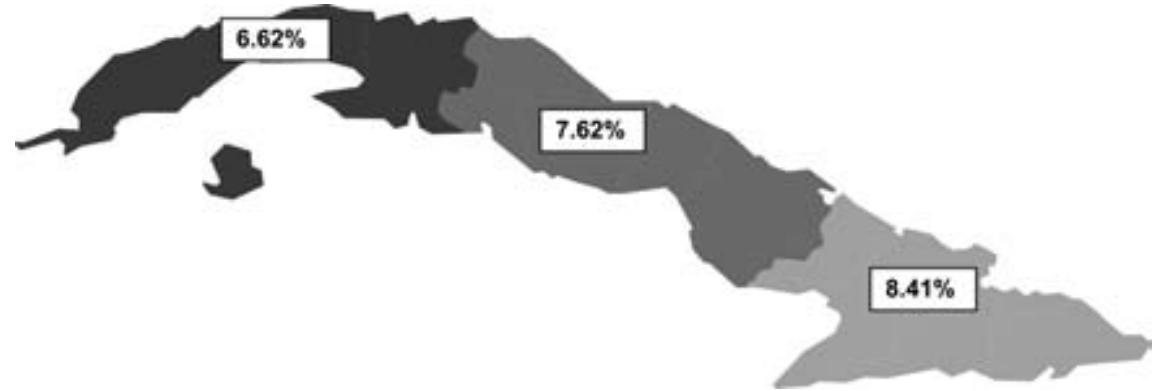

*Havana City and Sancti Spíritus provinces are still pending in this study.

Source: Analysis of results obtained from the National Study of Disabilities and Persons with Mental Retardation in Cuba, National Medical Genetics Center, Havana, 2003. 
Table 4: Maternal Alcohol Use During Pregnancy (MAP) Associated with Mental Retardation (MR) by Province, Cuba

\begin{tabular}{|lcccc|}
\hline Province & $\begin{array}{c}\text { MAP as \% } \\
\text { of Total MR }\end{array}$ & $\begin{array}{c}\text { MAP as \% of } \\
\text { Prenatal MR }\end{array}$ & $\begin{array}{c}\text { MAP as \% of } \\
\text { Dysmorphism }\end{array}$ & $\begin{array}{c}\text { MAP as \% of } \\
\text { Nonsyndromic MR }\end{array}$ \\
\hline Pinar del Río & 1.82 & 3.91 & 77.7 & 22.3 \\
\hline Havana Province & 2.10 & 4.30 & 23.9 & 76.1 \\
\hline Havana City & 4.68 & 13.26 & $*$ & $*$ \\
\hline Matanzas & 3.99 & 6.27 & 26.5 & 73.5 \\
\hline Isle of Youth & 2.71 & 4.47 & $*$ & $*$ \\
\hline Villa Clara & 2.26 & 4.93 & 15.9 & 84.1 \\
\hline Cienfuegos & 2.28 & 4.93 & 1.7 & 98.3 \\
\hline Sancti Spíritus & 1.40 & 5.19 & $*$ & 74.2 \\
\hline Ciego de Ávila & 2.62 & 5.39 & 25.8 & 71.7 \\
\hline Camagüey & 4.16 & 9.70 & 28.3 & 85.6 \\
\hline Las Tunas & 4.00 & 8.89 & 14.4 & 65.9 \\
\hline Holguín & 5.00 & 11.38 & 34.1 & 88.4 \\
\hline Granma & 5.09 & 7.67 & 11.6 & 81.5 \\
\hline Santiago de Cuba & 8.12 & 15.73 & 18.5 & 66.1 \\
\hline Guantánamo & 5.91 & 12.17 & 33.9 & 78.1 \\
\hline TOTAL & 4.22 & 9.38 & 21.9 & \\
\hline
\end{tabular}

*Unpublished data

Source: Analysis of results obtained from the National Study of Disabilities and Persons with Mental Retardation in Cuba, National Medical Genetics Center, Havana, 2003; and follow-up study by Genetic Counseling Master's Degree students (personal communications).

in the first years of life in children with DS in the central provinces. The main cause of death in DS in children is complications from congenital heart disease,[16] with values up to 60\%.[17] In this case, an epidemiological analysis complementary to our findings may generate conclusive answers to these questions. The chromosomic characterization in persons with DS in Cuba showed that the aneuploidy of chromosome 21 had the highest frequency, as is reported in the international literature[15] and also described in the karyotypes of 142 DS patients seen in institutions and clinical genetics services in Cuba.[18]

Figure 6: Maternal Alcohol Use in Pregnancy for Mothers with MR Offspring, with no History or Physical or Neurological Evidence of other Possible MR Causal Factors, by Region, Cuba

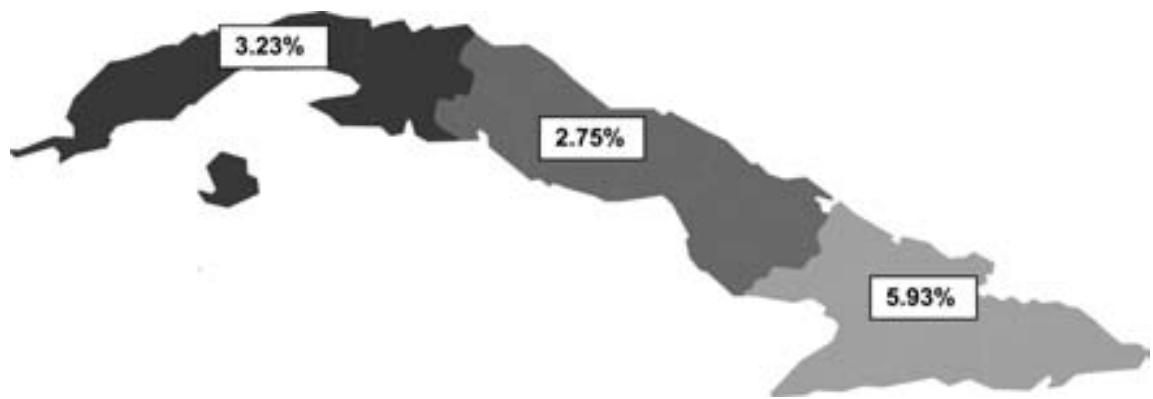

Source: Analysis of results obtained from the National Study of Disabilities and Persons with Mental Retardation in Cuba, National Medical Genetics Center, Havana, 2003.
Higher prevalence of MR in males has been observed historically in research involving populations with this disability.[19] In Cuba, a male(M)-female(F) ratio of $1: 1$ was registered in the last census.[20] However, in our study of 140,489 subjects with MR, this ratio was $1.46 \mathrm{M}: 1 \mathrm{~F}$; and in a study of 512 Cuban patients institutionalized due to SMR caused by prenatal and unclassifiable factors, the ratio was 1.5M:1F.[2] In Table 1, this marked male predominance is observed in persons with MMR classified as prenatal, psychosis, and unclassifiable; this is quite marked in the group aged $<15$ years among SMR cases.

Such differences had initially been attributed to various factors,[16] but advances in human genetics have now revealed that the X-chromosome carries a constellation of genes whose mutations are linked to MR.[21] The genotypic hemizygotic state of males may thus explain that a simple mutation - even recessive - may be biologically expressed, both in severe forms (even in complex syndromes) and in nonsyndromic forms of mental retardation.[22] The literature reports an MMR ratio as high as 1.9M:1F;[22] and 50\% of all MMR forms have been attributed to X-linked mutations.[21] At least 885 proteins expressed in the brain have also been identified, $40 \%$ of which have their genes in the X-chromosome.[22] This may explain the excess of males with MR of different degrees, especially in unclassifiable MR after genetic examination, based on the absence of family and prenatal history or dysmorphisms. Such mutations may be expressing for the first time in a male individual.

Fragile $X$ syndrome is the second genetic cause of mental retardation after Down syndrome,[14] and the first genetic cause determined by a mutation with Mendelian inheritance linked to the X-chromosome.[22] Unlike Down syndrome, the clinical diagnosis has its peculiarities. The phenotype may be easily recognized or suspected in the post-pubescent period by the presence of macroorchidism, but it is difficult to identify in childhood and its detection by dysmorphological and neurological indicators after birth is not possible.[23-25]

FXS prevalence in males has varied according to population studied and diagnostic methods used. In Nova Scotia, for instance, a serious epidemiological study found no evidence of this mutation in the screened population.[26] In other populations, values have been reported from 1 per 1,000 population to, more recently, 
1 per 6,000 population.[27] Making an assumption using this last prevalence value, we could expect a total of 938 individuals with FXS in the Cuban male population. In our study, the prevalence in the population of persons with MR, including men and women with the full mutation of FMR1, was low (1.19 per 1,000). In the general population, prevalence was as low as 1.52 per 100,000 population. The clinical screening criteria enabled detection of 86 males with full mutation in the molecular study, which is $26.4 \%$ of the 326 that classified with a clinical score, which represents a good level of detection.[10]

Today in Cuba, the study of this syndrome continues by regions. Very high prevalence has been detected, for example, in Cienfuegos and, particularly, in Rodas municipality, and to an even greater degree in the community of Rodas II. With a population of 2,530 male inhabitants, the FXS prevalence in Rodas II is high at 5.9 per 1,000 males. In this community, there are two families with a total of 15 males affected and 10 female carriers of the full mutation who also suffer MR, for a prevalence in the female population of full-mutation carriers of 4.0 per 1,000 females, and a prevalence for the community's entire population of 5.0 per 1,000 population.[28] Currently, the epidemiology of FXS in Cuba is the subject of further research; particularly to discover if there is a founder effect for this singular mutation in the country.[29]

\section{Consanguinity and MR}

An interesting phenomenon involved in the genesis of mental retardation is the detection of affected persons whose parents were consanguineous partners. The general frequency of this risk indicator observed in individuals with mild mental retardation explains the polygenic or multifactorial character of $10.91 \%$ of those with MR and $14.19 \%$ for the most severe forms of MR (Table 3). This denotes the possibility that other types of birth defects are involved, due to the high probability in marriages at risk for being heterozygotic for uncommon simple mutations that are only expressed in homozygotic persons, such as the specific metabolic defects of genetic syndromes with autosomal recessive inheritance.[30]

In one of the municipalities with the highest MR prevalence, Urbano Noris in Holguín province, high frequencies of consanguinity were also confirmed in persons with MMR and SMR. In this community, marriage between first cousins was so common that there was a frequency of $10.3 \%$ consanguinity in the Estrada area of town when the study was conducted. There are only 3 surnames in this community, and an MR rate of $10 \%$. Results of educational work concerning the risks of these marriages for their offspring may be changing couples' attitudes in this regard. In Estrada in 2003, 57.1\% of pregnancies were the result of consanguineous marriages. In 2004, there was a reduction in this phenomenon among expectant mothers (29.4\%), whereas in 2005, no history of consanguinity was found in the 14 pregnant women of this community.[31]

In Caimito in Havana Province, with a population of 34,672 and an MR prevalence of $0.68 \%$, it was found that consanguinity explained the presence of nonsyndromic MMR in $11.8 \%$ of people with MMR, and in 9.7\% of the syndromic forms with SMR.[32]

The frequency of consanguinity in parents of persons with MR is a changing phenomenon that varies in each country, and depends on the geographical characteristics and customs of the population.[33] In a study on consanguinity and MR in India, 160 (30.94\%) of 517 people studied were born from consanguineous marriages.[34]

In Cuba, consanguinity has been observed as a variable cause of MR. The highest values of consanguinity occur in the eastern region (Las Tunas, Holguín, Granma, and Guantánamo provinces, in that order), whereas in the western provinces, Pinar del Río showed the greatest frequency of this indicator (Table 3).

\section{Maternal Alcohol Consumption as a Cause of MR}

Another etiological prenatal factor for MR was alcohol consumption during pregnancy. In 5,934 persons with mental retardation, declaration of alcohol use during the whole pregnancy or part of it was the only prenatal antecedent for MR. Of these, $21.9 \%$ (Table 4) also showed dysmorphic signs that characterize fetal alcohol syndrome (FAS),[12] and in the rest the "hadegen" effect[35] of this common chemical teratogen was observed.

The clinical-genetic study undertaken in the country revealed provinces and municipalities more accustomed than others to consuming alcoholic beverages during pregnancy (Figure 6). In the eastern region, the highest values were detected in Santiago de Cuba, Guantánamo, and Holguín. Some of these, like Holguín, also coincide with the high consanguinity rate as a causal factor of MR.

In the Estrada community, a reduction of alcohol consumption during pregnancy has been observed in the last few years, from $72.2 \%$ in 2003 to $14.3 \%$ in 2005.[31] This behavioral change, the same as in consanguinity, can be attributed to reinforced educational efforts by trained professionals as a result of the national study.

\section{CONCLUSIONS}

The prevalence of MR in Cuba is lower than referenced values for developed countries. In this article, we provide original epidemiological data from clinical-genetic research in Cuba on 4 specific causal factors of MR, which we hope will contribute to new hypotheses for the study of the genetics of mental retardation and the environmental factors affecting embryo-fetal neurological development. Linking this new knowledge to diagnosis, treatment, and prevention of genetic disorders and birth defects, respecting bioethical principles, can lead to improved quality of life, as shown by some of the data mentioned in the discussion.

We hope that our findings will add to the knowledge base in Cuba for health professionals trained as specialists in medical genetics and genetic counseling as they carry out important educational activities at the national and community level, and for the National Network of Medical Genetics. In particular, it is hoped that public education on consanguinity and alcohol use during pregnancy will have positive effects on prenatal risk factors for MR.

Analysis of data for the 2 most frequent genetic causes of MR serves to inform public health authorities and decision-makers as they implement measures to improve prenatal detection of DS and to provide information to families with persons affected by 
FXS. The design of preventive strategies based on the technical and ethical foundations of genetic counseling is an expected benefit. At the same time, the epidemiological data point to the need for continued research focusing on the epidemiological and molecular characteristics of FXS in the Cuban population.
We concur with Byers who, when referring to genetic language applied to medical genetics and its ethical principles said, "if only we spoke the same language, we would have so much to discuss."[36] We would add that speaking the same language would improve the population's quality of life. 1 -

\section{REFERENCES}

1. Gustavson $\mathrm{KH}$, Hagberg B, Hagberg G, Sars K. Severe mental retardation in a Swedish county, II. Etiological and pathogenetic aspects of children born 1959-1970. Neuropaediatric 1977;(8):293-304.

2. Lantigua A, Mora F, Arechaederra M, Rojas I, Morales E, Rodriguez H, Viñas C, Noa CE, Barrios B. Etiological characterization of 512 severely mentally retarded institutionalized patients in Havana. Community Genetics 1999;(2):184-9.

3. Colectivo de Autores. Por la Vida. La Habana: Casa Editora Abril; 2003.

4. World Medical Association; Ethical Principles for Medical Research Involving Human Subjects. Tokyo: As amended and clarified; 2004.

5. UNESCO. Declaración Internacional sobre los datos genéticos humanos. París: 2003.

6. Torres O. Investigaciones con seres humanos para un mundo mejor. La experiencia de Cuba. In: Keyeux et al, editors. Etica de la investigación en seres humanos y políticas de salud pública. Bogotá: UNESCO y Red Latinoamericana y del Caribe: Universidad Nacional de Colombia; 2006.

7. Organización Mundial de la Salud; CIE 10. Décima revisión de la clasificación Internacional de las enfermedades. Trastornos mentales y del comportamiento. Ginebra: Organización Mundial de la Salud; 1993.

8. Willemsen R, Smits A, Mohkamsing S. Rapid antibody test for fragile $X$ syndrome: a validation of the technique. Hum Genet 1997;(99):308-11.

9. Lardoeyt Ferrer R, Lantigua Cruz A. Experiencias técnicas en el uso de la prueba inmunohistoquímica para el diagnóstico del síndrome frágil $X$. Rev Cubana Invest Biomed 2004;(23):259-65

10. De Vries BB, Mohkamsing S, van den Ouweland AMW, Mol E, Gelsema K, van Rijn $M$, Tibben A, Halley D, Duivenvoorden $\mathrm{HJ}$, Oostra BA, Niermeijer M. Screening for the fragile $X$ syndrome among the mentally retarded: a clinical study. J Med Genet 1999;(36):467-70.

11. Southern EM. Detection of specific sequences among DNA fragments separated by gel electrophoresis. J Mol Biol 1976;(98):50317.

12. Day NI, Richardson GA. Prenatal alcohol exposure: A continuum of effects. Semin Perinatl 1991;(15):271-9.

13. Colectivo de Autores. Informática médica. Bioestadística. Tomo 2. Capítulo 8. Estadística descriptiva. Editorial Ciencias Médicas, La Habana. 2004; pp 211-305.

14. Leonard $\mathrm{H}$, Wen $\mathrm{X}$. The epidemiology of mental retardation: Challenges and oppor- tunities in the new millennium. Ment Retard Dev Disabil Res Rev 2002;(8):117-34.

15. Baird PA, Sadovnick AD. Maternal age-specific rates for Down syndrome: Changes over time. Am J Med Genet. 1988;(29):917-27.

16. Mikkelsen M, Poulsen $H$, Nielsen KG. Incidence, survival and mortality in Down syndrome in Denmark. Am J Med Genet. 1990;Suppl 7:75-8.

17. Bacchichetti C, Lenzine E, Pegorano R. Down syndrome in the Belluno district (Veneto region, northeast Italy): Age distribution and morbidity. Am J Med Genet 1990 Suppl 7:84-6.

18. Viñas Portilla $C$, Lantigua Cruz A, Delgado Oceguera E. Down's syndrome: Cytogenetic characteristics in 142 patients. Rev Cubana Pediatr 1989;(61):36-43.

19. Penrose LS. A Clinical and Genetic Study of Mental Defects. Vol 229 HMSO, London, 1938.

20. Anuario Demográfico de Cuba 2001. La Habana: ONE; 2002.

21. Chelly J, Mandel JL. Monogenic causes of X-linked mental retardation. Nature Rev Genet 2001;(2):669-80.

22. Ropers HH, Hamel BCJ. X-linked Mental Retardation. Nature Rev Genet 2005;(6):46-57.

23. Lantigua Cruz A. Síndrome Down vs Síndrome frágil X. Educación 1998;93:19-95.

24. Lantigua Cruz A. Síndrome Frágil X: Mutaciones Dinámicas y su Repercusión en otras Enfermedades Genéticas. Rev Cubana Pediatr 1997;(69):37-47.

25. Lantigua Cruz A, Ravelo Amargos I, Halley D. Fragile $X$ syndrome: clinical, cytogenetic and molecular correlation in a family. Rev Cubana Pediatr 1997;(69):118-23.

26. Beresford RG, Tatlidil C, Riddell DC, Welch JP, Ludman MD, Neuman PE, Gree WL. Absence of fragile $X$ syndrome in Nova Scotia. J Med Genet 2000;(37):77-9.

27. Turner G, Webb T, Wake S, Robinson H Prevalence of fragile $X$ syndrome. Am $J$ Hum Genet 1996;(64):196-7.

28. Terroba A. Personal communication. 2006.

29. Buyle S, Reyniers E, Vits $L$ et al. Founder effects in Belgian-Dutch fragile $X$ population. Hum Genet 1993;(92):269-72.

30. Bittles $\mathrm{AH}$. The role and significance of consanguinity as a demographic variable. Population and Development review 1983;(20):561-83.

31. Marrero M. Personal communication. 2006.

32. Serrano L. Personal communication. 2006.
33. Hafez M, El Tahan H, Awadalla M, ElKhayat $\mathrm{H}$, Abdel-Gafar, Ghoneim M. Consanguineous matings in the Egyptian population. J Med Genet 1983;(20):56-60.

34. Madhavan T, Naravan J. Consanguinity and mental retardation. J Ment Defic Res 1991;(35):133-9.

35. Sampson PD, Strissguth AP, Bookstein FL et al. Incidence of fetal alcohol syndrome and prevalence of alcohol-related neurodevelopmental disorders. Teratology 1997; 56:317-26.

36. Byers PH. 2005 ASHG Presidential Address. If Only We Spoke the Same Language-We Would Have So Much to Discuss. Am J Hum Genet 2006;(78):368-72.

\section{THE AUTHORS}

Araceli Lantigua Cruz (Corresponding Author), Full Professor, Higher Institute of Medical Sciences of Havana. Clinical Genetics Specialist. Vice Director for Teaching, National Medical Genetics Center, Havana, Cuba. lantigua@infomed.sld.cu

Miriam Portuondo Sao, Instructor, Higher Institute of Medical Sciences of Havana. Family Medicine Specialist. Vice Director of the Program for the Disabled, National Medical Genetics Center, Havana, Cuba.

Teresa Collazo Mesa, Associate Researcher and Head, Molecular Genetics Laboratory, $\mathrm{Na}$ tional Medical Genetics Center, Havana, Cuba.

Roberto Lardoeyt Ferrer, Instructor, Higher Institute of Medical Sciences of Havana. Clinical Genetics Specialist, National Medical Genetics Center, Havana, Cuba.

\section{ACKNOWLEDGEMENTS}

This national study could not have been carried out without the support of the Cuban government, its support of Medical Genetics, and economic and organizational support from the Ministry of Public Health. We would also like to thank the Clinical Genetics specialists, the Master's Degree candidates in Genetic Assessment, and other researchers, technicians, and specialists of the National Medical Genetics Center, the 14 Provincial Medical Genetics Centers and 169 Municipal Centers, all part of the National Medical Genetics Network, who bring preventative and clinical care to the disabled and their families in Cuba. 